\title{
PREPARATION OF PLLA MEMBRANES WITH DIFFERENT MORPHOLOGIES FOR CULTURE OF LIGAMENT CELLS
}

\author{
I-Chi LeE, TAI-Horng Young \\ Institute of Biomedical Engineering, College of Medicine and Engineering, \\ National Taiwan University, Taipei, Taiwan
}

\begin{abstract}
Poly (lactic acid) is a biodegradable biomedical material that has been used for connective tissue reconstruction. In this work, poly-L-lactide (PLLA) membranes with different morphologies were prepared by phase separation method. Otherwise, biomaterials coated with various extracellular matrix (ECM) have been shown to promote cell adhesion, proliferation, and differentiation. In addition, the in vitro interaction of medial collateral ligament cells (MCLs) and PLLA membranes with dense, porous and particulate morphologies and with ECM coating was investigated. It was found that the cell compatibility of three types of PLLA membranes almost the same before coating ECM. The results also revealed that collagen type I could improve ligament cells adhesion and fibronectin could improve ligament cells growth, and this effect was most obvious in particulate membrane. Therefore, because the PLLA materials with particulate structure could adsorb more ECM which in turn influenced the cell adhesion and cell growth. The PLLA membrane with the particulate morphology satisfies the biomaterial requirement necessary for temporary scaffold to transplanted ligament cells and provides a means for the architectural design of more complex tissue-engineered systems.
\end{abstract}

Biomed Eng Appl Basis Comm, 2006(August); 18: 185-189.

Keywords: poly-L-lactide (PLLA); medial collateral ligament cells (MCLs); collagen type I; fibronectin

\section{INTRODUCTION}

Poly (L-Lactic acid) (PLLA), one of the few synthetic degradable polymers approved by the Food and Drug Administration (FDA) for certain human clinical applications, is a suitable substrate for connective tissue cells cultures and shows fracture

Received: Feb. 14, 2006; Accepted: June 1, 2006

Correspondence: Tai-Horng Young, Professor

Institute of Biomedical Engineering, College of

Medicine and Engineering, National Taiwan

University, Taipei 100, Taiwan

E-mail: thyoung@ha.mc.ntu.edu.tw healing results comparable to those of metallic implants. Generally, most of PLLA substrates for cell culture have dense and smooth surface morphology. Since the biocompatibility of a substrate is also influenced by its surface morphology, salt-leaching technique has been used to generate porous morphology of biodegradable polymers to improve cell growth and new bone tissue formation.

The anterior cruciate ligament (ACL), an intraarticular ligament of the knee, is an important joint stabilizer that is frequently injured in sports and exercise. In the United States alone, over 100,000 ACL reconstruction surgeries are performed annually [1]. 
Ligaments consist of approximately $75 \%$ of collagens ( $90 \%$ is type I and $10 \%$ is type III) and less than $1 \%$ of elastin, proteoglycans, and glycoproteins. Fibroblasts represent $20 \%$ of tissue volume, whereas the extracellular matrix makes up $80 \%$. The complex anatomy of the human ligaments is dependent on the interaction, orientation, and relationships between molecules, such as matrix proteins, and cells. Therefore, extracellular matrix plays an important role in ligament tissue engineering [2-4].

Protein modification of biomaterials has been reported to improve cell adhesion [5-8] and control the subsequent cellular response to material surfaces [910]. Current strategies in improving cell attachment and augmenting subsequent cellular response include pre-coating these surfaces with molecules such as laminin, fibronectin (Fn), collagen, and so on. These studies demonstrate that modifying the biomaterial surface with cell adhesion molecules such as Fn has a beneficial effect on cellular response and tissue repair. In addition to being one of the most abundant extracellular glycoproteins found in the body, Fn is reported to be up-regulated during ligament formation and wound healing [11-13]. The utilization of Fn in MCL tissue-engineering scaffolds has not been explored.

In this study, the PLLA substrates were used in the form of membranes. PLLA membrane surfaces with different surface morphologies were prepared by the phase inversion method [14]. The morphologies of PLLA membranes were investigated by scanning electron microscopy (SEM). Medial collateral ligament cells were selected to evaluate the behaviors of ligament cells on the prepared PLLA membranes. Here we measured, including cell adhesion and cell growth examined by SEM and MTT assay. Besides, we try to coat two kinds of extracellular matrix on PLLA membranes and examined the biocompatibility. The results of the investigation showed the particulate membrane provides a new surface morphology for improving the design and production of PLLA biomaterials intended for ligament regeneration.

\section{MATERIALS AND METHODS}

\subsection{PLLA Membrane Fabrication}

Poly (L-Lactide)(PLLA) was supplied by Sigma. The weight average molecular weight $\left(\mathrm{M}_{\mathrm{W}}\right)$ of PLLA was $85000-160000$ as determined by gel permeation chromatography. The PLLA membranes were prepared by the dry process and wet process of the phase inversion method. Polymer solution was cast on a glass plate in a uniform thickness of $300 \mu \mathrm{m}$ by an autocoater (KCC303, RK print-coat Instruments,
UK) at $25^{\circ} \mathrm{C}$ for the preparation membranes. In this work, three types of PLLA membranes were prepared by changing the phase inversion process. The casting solution was evaporated at $25^{\circ} \mathrm{C}$ for 1 day to obtained dense membrane . Particulate membrane and porous membrane were prepared by immersing the casting solution immediately into the Ethanol bath for 30 minutes. The polymer concentration of porous was $5 \%$ and $20 \%$ of particulate membrane. After the evaporation or precipitation was completed, the formed membranes were soaked in water to remove the residual solvent and freeze-dried to remove the water.

\subsection{Cell Culture}

Medial collateral ligament (MCL) tissue samples were isolated from New Zealand white rabbits $(1.5 \mathrm{~kg})$ and rinsed with phosphate-buffered saline (PBS). The culture medium used was modified Eagle's medium (MEM) supplemented with $10 \%$ fetal calf serum (Gibco-RBL Life Technologies, Paisley, UK) and antibiotic/antimycotic (penicillin G sodium $100 \mathrm{U} / \mathrm{ml}$, streptomycin $100 \mathrm{U} / \mathrm{ml}$, amphotericin B $0.25 \mu \mathrm{g} / \mathrm{ml}$, Gibco-BRL Life Technologies, Paisley, UK). Ligament cells were trypsinized using $0.1 \%$ trypsin and $0.1 \%$ ethylenediaminetetraacetic acid for $5 \mathrm{~min}$, centrifuged at $400 \mathrm{~g}$ for $5 \mathrm{~min}$, and resuspended in the medium.

\subsection{Membrane Surface Modification and Cell Seeding}

For determination of the cell adhesion and cell growth, the prepared PLLA membranes with $15-\mathrm{mm}$ in diameter were placed in 24-welled tissue culture polystyrene plates (Costar, U.S.A.). A silicon rubber ring $15-\mathrm{mm}$ diameter was placed on each of the tested membranes in the wells to prevent them from floating. Membranes and silicon rubber rings were sterilized in $70 \%$ alcohol overnight and rinsed extensively with phosphate buffered saline (PBS), followed by treatment under ultraviolet light overnight. To improve cell attachment, the membrane surface was modified by coating the sample with Fn and collagen solution. In this process, the polymer membranes were precoated in the fibronectin and collagen solution, respectively. The Fn solution concentration used for this study was $10 \mu \mathrm{g} / \mathrm{ml}$ and $1 \mu \mathrm{g} / \mathrm{ml}$ for collagen. Subsequently, $1-\mathrm{ml}$ medium of cell suspension at a density of $1 \times 10^{5}$ cells / $\mathrm{ml}$ was added to each well and maintained in a humidified atmosphere with $5 \% \mathrm{CO}_{2}$ at $37^{\circ} \mathrm{C}$.

\subsection{MTT Assay}

After cell culturing for 1 , and 4 days, the viability of ligament cells was determined by MTT assay. The method of Mosmann was modified and used in this 
study. The $100 \mu 1$ of MTT (SIGMA; USA) solution was added to each well. After 3 hours incubation at 37 ${ }^{\circ} \mathrm{C}, 200 \mu 1$ of dimethyl sulfoxide (Nacalai Tesque, Japan) was added to dissolve the formazan crystals. The dissolvable solution was jogged homogeneously about 15 minutes by the shaker. The optical density of the formazan solution was read on an ELISA plate reader (ELx 800, BIO-TEK, ) at $570 \mathrm{~nm}$.

\subsection{Cell Morphology}

Cells adhering to the membranes were washed with phosphate buffered saline (PBS) after 4 and $24 \mathrm{~h}$ incubation. Subsequently, the cells were fixed with $2.5 \%$ glutaraldehyde in PBS for $1 \mathrm{~h}$ at $4^{\circ} \mathrm{C}$. The specimens, after being thoroughly washed with PBS, were dehydrated using graded ethanol changes, critical point dried, gold splattered in vacuum, and examined using SEM.

\section{RESULTS AND DISCUSSION}

In this article PLLA membranes with dense, porous and particulate morphologies were easily prepared by the phase inversion method and the behavior of ligament cells on these PLLA membranes were compared. Figure 1 displayed the morphologies of MCL cells were all fibroblast-like and the morphology was spindle. Otherwise, most of the average size of MCLs were almost smaller than $100 \mu$ $\mathrm{m}$. Because the cells were released from the MCL tissue, the cell density close tissue is higher than other sites. Figure 2 depict the top surface structure of three kinds of PLLA membranes : particulate, porous, and dense. The discussion of membrane morphology is published on biomaterials [14].

The results in Figure 3 depict the MTT conversion of cells attached to three types of membranes after 1,4

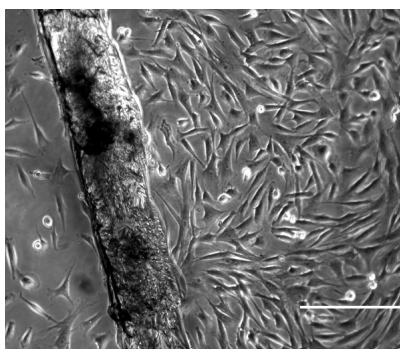

(a)

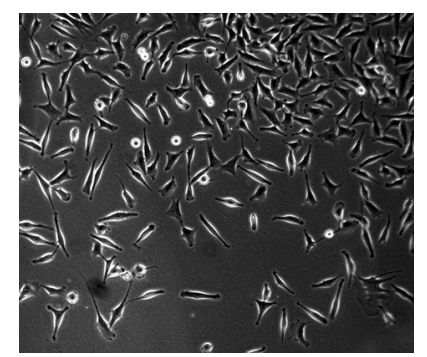

(b)
Fig. 1. Phase-contrast photomicrographs of MSCs isolated from New Zealand rabbit: (a) MCL cells with tissue isolated from rabbit (b) MCL cells isolated from rabbit $(\mathrm{Bar}=\mathbf{2 0 0} \mu \mathrm{m})$.

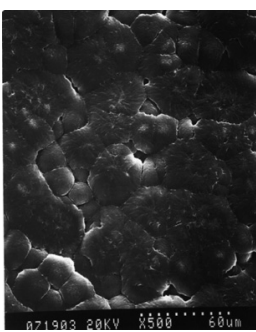

(a)

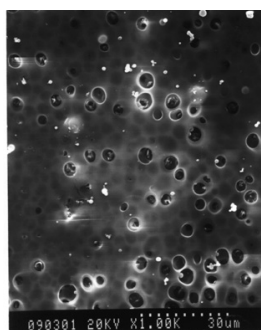

(b)

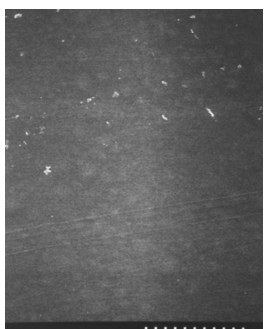

(c)
Fig.2. SEM photographs of the PLLA membrane (a) particulate (b) porous (c) dense (Ref15).

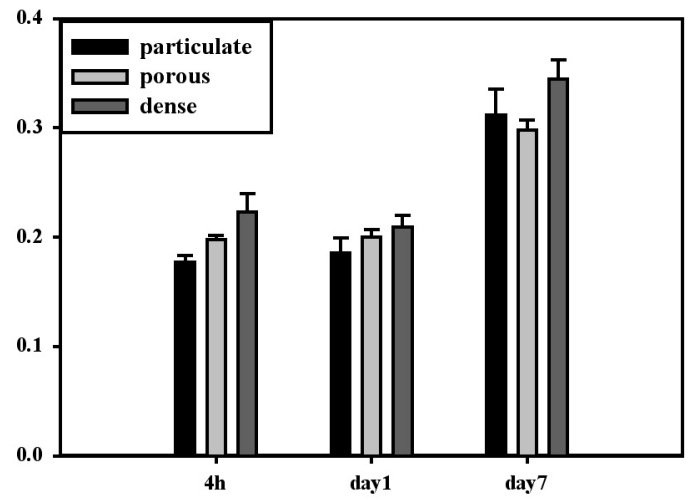

Fig. 3. The result of MTT test of MCL cells culture on three types of PLLA membranes.

and 7 days in culture. The results revealed that the OD value without obvious difference between three types of PLLA membranes. We have seed cells on three types of PLLA membranes and the results reveal the particulate membrane have the best biocompatibility which have been published on Biomaterials. However, the response of MCLs is different from the osteoblasts. It is suggested that the size of MCL cells is larger than osteoblasts, therefore, the particulate effect couldn't be observed in this study. However, after the PLLA membranes coated with ECM which included collagen type I and fibronectin, there's a distinctive effect could be observed. The results in Figure 4 and Figure 5 depict the MTT conversion of cells attached to three types of membranes with fibronectin and collagen coating after 1,4 ,and 7 days in culture. Figure 4 depict after 7 days incubation, particulate membrane coated with fibronectin showed the highest OD value. Figure 5 depict particulate membrane coating collagen showed the highest $\mathrm{OD}$ value after $4 \mathrm{~h}$ incubation. It is very interesting that although the cell biocompatibility were almost the same on the three types of PLLA membranes, but it showed the different results after ECM coating. This suggests that collagen could assist cell adhesion of MCL cells, and fibronectin could 


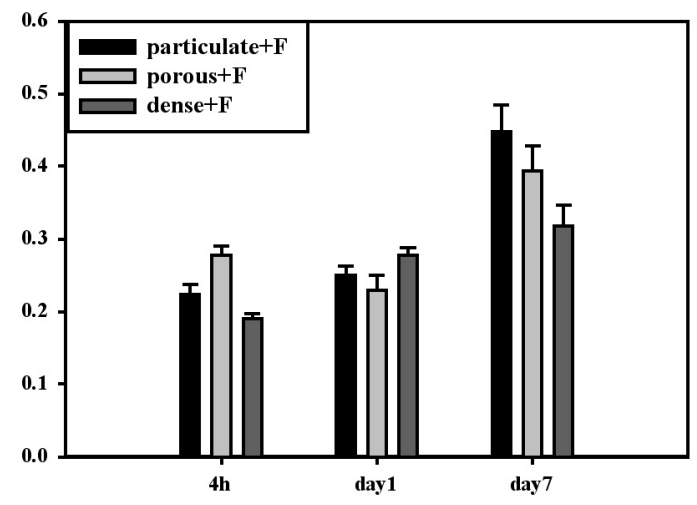

Fig. 4. The result of MTT test of MCL cell culture on three types of PLLA membranes coated Fibronectin.

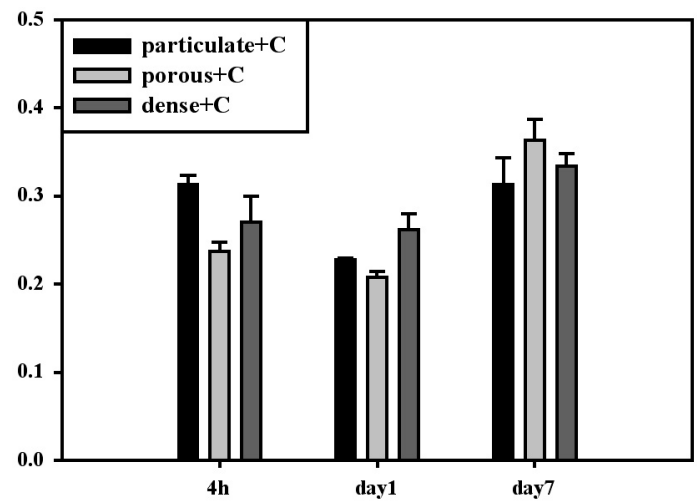

Fig. 5. The result of MTT test of MCL cell culture on three types of PLLA membranes coated collagen.

assist the cell proliferation. Besides, the effect is more obviously on particulate membrane. It is considered that maybe the particulate membrane with more surface areas that could adsorb more ECM, therefore, after coating with ECM, particulate membrane had the best biocompatibility.

Since the PLLA membrane structure is dependent on the polymer concentration in the casting solution, it is a good model to compare the effect of membrane surface structure on the ligament cell responses. However, it is not possible to observe cells on the prepared membranes by using light microscopy due to poor optical transparency. Therefore, scanning electron micrographs of MCL cells on the prepared membranes were studied to observe the cellular phenomenological behavior. Figure 6 (a), (b), and (c) shows the morphology of MCL cells attached on the various surface of PLLA membranes after cultured for $4 \mathrm{~h}$. Surface morphology were almost the same on three types of PLLA membranes. Figure 6 (d), (e), and (f) shows the morphology of MCL cells attached on the

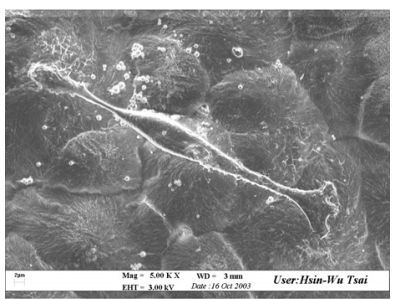

(a)

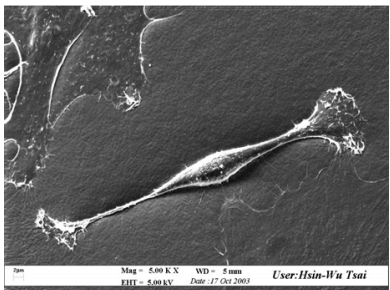

(c)

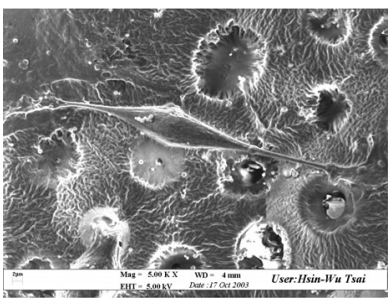

(e)

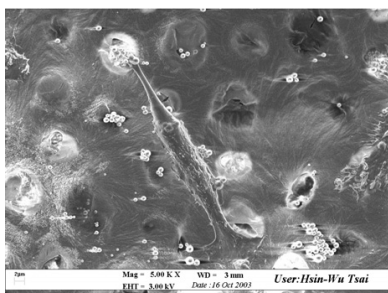

(b)

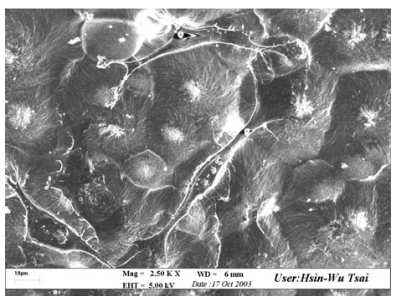

(d)

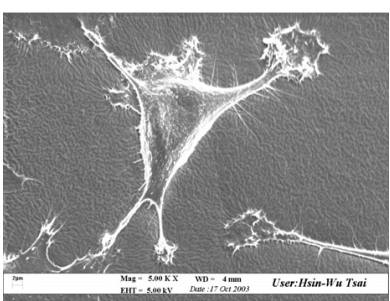

(f)
Fig. 6. SEM photographs of MCL cells cultured on the (a) particulate, (b) porous, (c) dense (d) particulate with collagen (e) porous with collagen (f) dense with collagen PLLA membranes after $4 \mathrm{~h}$ incubation.

various surface of PLLA membranes coating with collagen after cultured for $4 \mathrm{~h}$. In contrast, cells on the membranes with coating collagen can be considered well spread. Combine the MTT test and SEM photographs, it is suggested that the collagen type I is an very important ECM for ligament cell adhesion and fibronectin could supply better environment for ligament cells long term culture. Otherwise, particulate membrane is a new type material which could supply more areas than dense and porous membranes for ECM adsorption and indirect with better cell biocompatibitily. 


\section{CONCLUSION}

In this paper, a new particulate membrane was developed that could supply more surface area to adsorb more extracellular matrix. The results revealed that collagen could help cell adhesion and fibronectin could facilitate cell growth. It is considered that to change the Grain size and pore size of PLLA membrane will affect the cell adhesion and growth. This outcome could be applied to the regeneration of ruptures ligament.

\section{ACKNOWLEDGMENT}

The authors thank the National Taiwan University Hospital and the National Science Council of the Republic of China for their financial support.

\section{REFERENCES}

1. Jackson DW, Heinrich JT, Simon TM. Biologic and synthetic implants to replace the anterior cruciate ligament. Arthroscopy 1994;10(4):442-52 [Review] [57 refs].

2. Goulet F, Germain L, Rancourt D, Caron C, Normand A, Auger FA. Tendons and ligaments. In: Lanza R, Langer R, Chick W, editors. Principles of tissue engineering. Austin, TX: RG Landes Co. and Academic Press; 1997: 633-643.

3. Carlstedt CA, Nordin M. Biomechanics of tendons and ligaments. In: Nordin M, Frankel VH, editors. Basic biomechanics of the musculoskeletal system. Malvern, PA: Lea \& Febiger; 1989: 59-74.

4. Laurencin CT, Ambrosio AMA, Borden MD, Cooper JA Jr. Tissue engineering: orthopedic applications. Annu Rev Biomed Eng 1999;1:19-46.

5. Bhati RS, Mukherjee DP, McCarthy KJ, Rogers SH, Smith DF, Shalaby SW. The growth of chondrocytes into a fibronectincoated biodegradable scaffold. J Biomed Mater Res 2001;56(1):74-82.

6. Ma Z, Gao C, Shen J. Surface modification of poly-L-lactic acid (PLLA) membrane by grafting acrylamide: an effective way to improve cytocompatibility for chondrocytes. J Biomater Sci Polym Ed 2003;14(1):13-25.

7. Wan Y, Yang J, Yang J, Bei J, Wang S. Cell adhesion on gaseous plasma modified poly-(Llactide) surface under shear stress field. Biomaterials 2003;24(21):3757-64.

8. Ohya Y, Matsunami H, Yamabe E, Ouchi T. Cell attachment and growth on films prepared from poly(depsipeptide-co-lactide) having various functional groups. J Biomed Mater Res 2003;65A(1):79-88.

9. Hubbell JA. Bioactive biomaterials. Curr Opin Biotechnol 1999;10(2):123-9.

10. Garcia AJ, Vega MD, Boettiger D. Modulation of cell proliferation and differentiation through substrate-dependent changes in fibronectin conformation. Mol Biol Cell 1999;1910:785-98.

11. Hubble J, Eisenthal R, Whish WJ. A model for the initial phase of cell/surface interactions based on ligand binding phenomena. Biochem J 1995;311(Pt 3):917-9.

12. Amiel D, Foulk RA, Harwood FL, Akeson WH. Quantitative assessment by competitive ELISA of fibronectin $(\mathrm{Fn})$ in tendons and ligaments. Matrix 1989;9(6):421-7 [erratum appears in Matrix 1990;10(3):206].

13. Makisalo SE, Paavolainen PP, Lehto M, Skutnabb K, Slatis P. Collagen types I and III and fibronectin in healing anterior cruciate ligament after reconstruction with carbon fibre. Injury 1989;20(2):72-6.

14. Connor NS, Aubin JE, Sodek J. Independent expression of type I collagen and fibronectin by normal fibroblast-like cells. J Cell Sci 1983;63:233-44.

15. Liu HC, Lee IC, Wang JH, Yang SH, Young TH. Preparation of PLLA membranes with different morphologies for culture of MG-63 Cells. Biomaterials 2004;25: 4047-4056. 